Trabajos de Prehistoria

48, 1991 , pp. $383-393$

\title{
LA CRIPTOGAMIA: CIENCIA COMPLEMENTO DE LA ARQUEOLOGIA
}

POR

\author{
JOSE ANTONIO LOPEZ (*) \\ PEDRO MANUEL DIAZ (**) \\ JOSE JUAN SANCHEZ (**)
}

RESUMEN La importancia que la Criptogamia debe tener como fuente auxiliar de la Arqueología, queda de manifiesto por el numeroso número de datos que desde la Ecología y la Palinología nos facilitan las criptógamas. La relación entre éstas y el hombre ha sido puesta de manifiesto en distintas culturas, por lo que su utilización en estudios paleoambientales puede jugar un papel sumamente interesante para delimitar con mayor precisión el hábitat en que se desenvolvió el hombre.

ABSTRACT The importance that Cryptogamy might have as an auxiliar y source of Archaeology can be glimpsed from the large amount of data of criptogamic plants in ecological and palinological studies.

The relation between these kind of plants and man has been observed in different cultures. Therefore, its use for paleoenvironmental investigations, as complementary indicators of human presence, could be really interesting in order to establish with more precision the habitat in which man has developed.

Palabras clave Criptogamia. Arqueoecología. Palinología. Esporas.

Key words Cryptogamy. Archaeoecology. Palinology. Spores.

\section{INTRODUCCION (1)}

La Arqueoecología es el estudio del ambiente durante el lapso abarcado por la Arqueología para

(־) Dpto. de Biología Vegetal I. Fac. de Biología. Universidad Complutense de Madrid.

(*) Dpto. de Prehistoria. Centro de Estudios Históricos. CSIC Madrid.

(1) Este artículo forma parte del Proyecto «La dialéctica hombre-medio ambiente en el Mediodía peninsular: la perspectiva arqueológica» (PB 88 - 0080), llevado a cabo en el Dpto. de Prehistoria, Centro de Estudios Históricos (CSIC). 
el estudio de la historia humana y la evolución de la cultura y de la sociedad (D'Antoni, 1979). Esta rama de la Arqueología se superpone en parte, al objeto de estudio de la Paleoecología, rama de la Ecología que estudia ambientes anteriores al actual. Ambas ciencias recurren al estudio de los fósiles, en sentido amplio, como método que facilite las interpretaciones para cubrir su propósito.

La Criptogamia es la rama de la Botánica que estudia las plantas sin flores llamadas "criptógamas». Algunos de los Phyla tradicionalmente considerados como tales, hoy día han sido excluidos del Reino Vegetal, como por ejemplo los hongos; aunque siguen estudiándose por convención dentro de la Criptogamia.

El hombre ha mostrado su interés por las criptógamas desde tiempos remotos, por su utilidad en la gastronomia, la farmacopea, etc. Esta relación con el hombre está atestiguada arqueológicamente.

La Palinología ha sido aceptada como uno de los métodos más completos para obtener interpretaciones arqueoecológicas, si bien no es el único que puede aportarnos información para la reconstrucción de paleoambientes. El análisis polínico de sedimentos procedentes de yacimientos arqueológicos, así como de turberas es un conjunto de técnicas y modelos de interpretación arqueoecológicos, de mostrado valor. El avance de la Palinología a nivel taxonómico nos permite determinar los granos de polen hasta niveles lo suficientemente válidos como para poder considerarlos con absoluta fiabilidad como fuente indicadora de situaciones cambiantes en las condiciones ambientales.

En el caso de las criptógamas, los estudios polínicos no se refieren al polen en sí, por carecer de él, ya que son vegetales sin flores, sino a sus esporas. La espora es la unidad reproductora de las criptógamas, presentando un polimorfismo acusado, sobre todo en ciertos grupos, así como un origen igualmente variado, ya sea a través de una reproducción sexual o asexual. En muchos casos, las esporas suponen estadios de letargo y protección ante condiciones ambientales desfavorables.

Los estudios polínicos referentes a esporas de criptógamas están menos desarrollados que en el caso de los granos de polen. Es por ello que en las interpretaciones paleoambientales procedentes del estudio de diagramas polínicos se suele obviar la información que nos pueden proporcionar las esporas. No cabe duda que a tal efecto la Criptogamia pasa por ser una ciencia desconocida para el arqueólogo. A nivel botánico, la Palinología de criptógamas es una rama más de las ciencias biológicas, y como tal, ha experimentado un desarrollo notable en los últimos años. El arqueólogo no debe menospreciar tal información, pues, como ya se ha indicado con anterioridad, las critógamas responden en numerosas ocasiones a condiciones microambientales muy concretas, que definirían con alta precisión el hábitat humano. Así pues, no cabe duda de la "potencial" ayuda que puede prestar a estudios paleoecológicos, de gran interés para la Arqueología.

Nuestra propuesta es examinar otros datos paleoecológicos que complementen las interpretaciones palinológicas. Las evidencias de restos de criptógamas podrían servir de gran ayuda como indicadores ecológicos, sobre todo, en combinación con la del polen fósil, para las interpretaciones paleoambientales en relación con las culturas humanas.

El propósito de este trabajo es of recer al arqueólogo un abanico de las relaciones entre la Arqueología y la Criptogamia que pueden ser utilizadas tanto desde el punto de vista científico como cultural.

\section{LOS REINOS BIOLOGICOS: CAMPO DE ESTUDIO DE LA CRIPTOGAMIA}

A medida que se consideran organismos más simples, la distinción entre plantas y animales se hace más difícil (Cronquist, 1978). Así, muchas algas unicelulares son estudiadas tanto en Zoología como en Botánica. Los hongos han sido entendidos durante mucho tiempo como integrantes del Reino Vegetal, pero sus paredes celulares son de quitina en lugar de estar formadas por celulosa, hecho común en el resto de vegetales. Una de las formas intermedias más interesantes es Euglena, que de ordinario tiene clorofila y elabora su propio alimento, pero posee una citofaringe. Aunque aparentemente no lo ingiera a través de ella, organismos similares y afines sí que lo hacen, carenciendo de clorofila. Incluso en Euglena se ha podido llegar a definir el inicio de un sistema nervioso, indicado por la 
presencia de una mancha ocular sensible a la luz. Aunque es difícil negar que cualquier organismo que posea clorofila sea una planta, se debe admitir en este caso que el conjunto de aspectos anteriormente citados, asemejan muy mucho a Euglena con organismos definidos según todos los criterios como verdaderos animales, algunos de los cuales son realmente afines a ella.

La clasificación de los organismos en dos reinos biológicos, el vegetal y el animal, es natural y hasta cierto punto didáctica, pero no es absoluta. Es por ello que la clasificación de las plantas ha sufrido numerosas alteraciones desde Aristóteles (384-322 a. C.) y Teofrasto (372-287 a. C.), su discípulo, que los agrupaban en árboles, arbustos e hierbas (Smith, 1955). Algunas han consistido en reconocer tres o más reinos de organismos en lugar de dos.

Ninguno de esos esquemas parece tener una aceptación tan amplia como para ser aceptado totalmente válido. No obstante, creemos necesario realizar una pequeña revisión de los mismos a fin de dar a conocer al arqueólogo los distintos Reinos Biológicos y con ello la verdadera extensión y contenido que debería poseer la Criptogamia como ciencia.

Ya Linneo en 1735 dividió al Reino Vegetal en 24 clases a partir de un sistema artificial de clasificación basado en los caracteres sexuales de las plantas. Una de estas clases, la 24, era Cryptogamia, que incluía a todas las plantas con órganos reproductores no evidentes: "CRYPTOGAMIA continet Vegetabilia, quorum Fructificationes oculis nostris se subtrahunt, \& structura ab aliis diversa gaudent». Dentro de ella incluía no sólo a los helechos, musgos, algas y hongos, sino también algunas plantas superiores con flores difíciles de reconocer (Lemna y Ficus) y, asimismo, corales y esponjas, grupos animales claramente definidos como tales.

No obstante, fue Haeckel (1866) quien a mediados del siglo XIX creó un nuevo reino, el Reino de los Protistas, para todos aquellos organismos que no podían figurar ni en el Reino Animal ni en el Vegetal. Comprendía fundamentalmente grupos de protozoos, pero también algunos que hoy no se estudian como tales (Fernánde7-Galiano, 1990). Algunas de las clases consideradas por Haeckel (1878) han sido estudiadas con asiduidaa dentro de la Criptogamia, concretamente las llamadas Fungi y Mixomycetes.

A partir de 1980 va tomando fuerza entre los biólogos la clasificación de los seres vivos en cinco Reinos: Monera, Protista, Plantae, Fungi y Animalia. Expuesta por primera vez por Whittaker (1969) y modificada posteriormente por Whittaker y Margulis (1978), supone la primera separación en dos reinos diferentes de los seres unicelulares: los procariotas (seres vivos cuyas células carecen de núcleo y membrana nuclear, así como de estructuras flagelares $9+2$ ) en el Reino Monera y los eucariotas en el Reino Protista, que sí poseen dichas unidades estructurales.

No obstante, otras establecen seis reinos (Cavalier-Smith, 1983), siete (Edwards, 1976), nueve (Cavalier-Smith, 1981) e incluso trece (Leedale, 1974). En la actualidad, la más aceptada es la de Whittaker y Margulis (1978), versión esta muy promulgada y defendida por uno de sus autores (Margulis, 1981 y 1974).

Llegamos, pues, a la conclusión de que la clasificación de los seres vivos en un número determinado de reinos biológicos juega un papel sumamente dinámico, en cuanto que ciertos organismos puedan incluirse según el autor en uno u otro reinos. Los representantes del ya citado género Euglena han sido incluidos tanto en el Reino Protista (Corliss, 1984; Puytorac \& cols., 1987) como en el Reino Plantae dentro de los grupos de algas (Bold \& Wynne, 1985; Des Abbayes \& col., 1989). Ahora bien, para el propósito de este trabajo, estos problemas taxonómicos no deben tener tanta importancia como la que sí debe darse a la ecología y valor de indicación de tales organismos. Es por ello que, nos centraremos primordialmente en este aspecto, pues nos parece de mayor valor al arqueólogo y a las interpretaciones a realizar por éste.

\section{ARQUEOECOLOGIA}

Una concepción moderna de la Arqueología convierte a ésta en una ciencia interdisciplinar. La integración de reconstrucciones arqueológicas realizadas desde distintos campos de trabajo nos 
ofrece un cuadro del pasado mucho más ajustado a la realidad de lo que la Arqueología tradicional conseguía. En particular, las ciencias naturales han demostrado ser de gran ayuda y validez para el arqueólogo.

El «actualismo ambiental» fue un método de trabajo válido mientras no existiera forma de poder cuestinarlo. El avance de otras disciplinas, principalmente de la Paleoecología, consiguió superarlo.

Los sistemas sociales se desarrollan de manera interactuante con los naturales, ampliando la complejidad de los ecosistemas. Dicha interrelación condiciona la dinámica evolutiva de ambos. D'Antoni (1979) define a la Arqueoecología como el estudio de la estructura y proceso de sucesión del ecosistema a raíz de la integración del hombre en él. Mediante una interpretación conjunta de las variables, la Arqueoecología debe constituirse en una de las vertientes que compongan una visión globalizadora del hombre y del ambiente, a través de su proceso histórico.

La Arqueoecología tiene su primer auge en las décadas de los sesenta y setenta, principalmente a cargo de científicos nórdicos y anglosajones (Berglund, 1977; Butzer, 1964; Gray, 1962; Straever, 1971; etc.). En España, una de las líneas de investigación arqueológica se ha basado en el análisis de paleomuestras vegetales, ya sean restos de polen fósil (Paleopalinología), carbones fosilizados (Antracología) o semillas fosilizadas (Paleocarpología); destacándose los trabajos de Dupre Ollivier (1988), López García (1980 y 1986) y Rivera y col. (1988). Como se ha dicho, por nuestra parte, proponemos abrir otra basada en aquellos datos ofrecidos por la Criptogamia, referidos principalmente al Cuaternario.

\section{EL HOMBRE Y LA ECOLOGIA DE LAS CRIPTOGAMAS}

Bajo la denominación de "criptógamas" se agrupa un amplísimo elenco de seres vivos, de biología y origen muy distintos. Por ello, la amplitud ecológica de las criptógamas abarca prácticamente todos los medios de vida de la biosfera, desde suelos, aguas dulces y saladas, materia orgánica, etc.; habiéndose adaptado a las condiciones más extremas tales como zonas salobres, volcánicas, hielos, etc. Cabe preguntarse qué organismos resultan de mayor interés al arqueólogo. La primera respuesta que obtendríamos es que las critógamas de ecosistemas terrestres son nuestro principal objeto de estudio, ya que constituirían parte del hábitat vital del hombre. Por otra parte, sólo los restos que aparecen con una frecuencia estadísticamente alta, y con posibilidades de identificación, pueden aportarnos alguna información arqueoecológica.

Básicamente nos centraremos en el estudio de hongos, briófitos y criptógamas vasculares. No obstante, y con anterioridad, haremos mención a otros fósiles de critógamas, procedentes de grupos botánicos distintos a los antes nombrados, pero que por el hecho de guardar un interés notable en estudios paleoecológicos son de gran ayuda para la Arqueoecología.

\section{Algas}

Determinadas algas de agua dulce (diatomeas, dinoflagelados, crisófitos, etc.) son extraordinariamente sensibles a cambios climáticos regionales. Así, ha sido posible en determinados casos, conocer la historia del clima a partir de la sucesión de estos organismos en sedimentos lacustres o marinos (Ybert, 1988; Margalef, 1956). Los hongos, briófitos y critógamas vasculares responden más a condiciones meso y microclimáticas que al clima regional. Por ello, poseen mayor valor como indicadores que otros seres vivos, tales como árboles $\mathrm{u}$ otras fanerógamas (plantas con flores) angiospermas (de semilla cubierta) definidoras de paisaje.

La combinación de la información aportada por angiospermas y criptógamas fósiles nos permite una mayor precisión en la reconstrucción de paleoambientes. Un bosque no es únicamente el 
conjunto de especies arbóreas o arbustivas que lo forman, sino toda una comunidad de seres vivos entre los que se establecen fuertes relaciones de interdependencia. Todos ellos son, en mayor o menor medida, posibles indicadores del estado de conservación de las formaciones boscosas y, por lo tanto, fuente de información sobre las actividades humanas llevadas a cabo en el bosque, tales como la quema, agricultura, pastoreo, etc., que nos marcarían el grado de desarrollo de la cultura humana.

\section{Briófitos}

Los briófitos (musgos, hepáticas y antocerotas) necesitan por lo general condiciones de humedad alta. Si el agua les falta sus funciones vitales no pueden llevarse a cabo dada su condición de poiquilohidros. Pueden vivir sobre suelos, rocas, epífitos e incluso algunas especies son acuáticas.

Los restos de briófitos son muy frecuentes durante todo el Cuaternario, lo que nos permite usarlos como fuente de información arqueoecológica. Los más usuales son las esporas, así como los filidios y esporofitos contenidos en el ámbar.

Muchos briófitos están íntimamente asociados con plantas vasculares, estando confinados a localizaciones particulares en comunidades formadas por ellas (Schofield, 1985) y juegan un importante papel en la dinámica de tales asociaciones. La extensión de ciertos briófitos en determinados momentos puede significar, por ejemplo, un cambio notable en el balance hídrico del bosque. Las actividades del hombre han destruido numerosas áreas de hábitats propios de briófitos, siendo posible que ciertos taxones se hayan extinguido en tal proceso.

En cambio, ciertos musgos y hepáticas se ven favorecidos por una mayor actividad humana sobre el medio, proliferando de manera notable si las condiciones son las adecuadas. Dentro de este grupo de especies que habitarían en ambientes ligeramente nitrificados, necesitados de suelos ricos en sales minerales, principalmente en ambientes humanizados o frecuentados por animales, podrían incluirse: Marchantia polymorpha, Lunularia cruciata, Leptobryum pyriforme, Funaria hygrometrica, Barbula convoluta, Bryum. argenteum, Ceratodon purpureus, etc. Así, en los últimos años son frecuentes los trabajos que denotan la presencia de briófitos en ambientes urbanos de la Península Ibérica (Ron y col., 1987).

Importante es, pues, la información arqueoecológica que nos pueden ofrecer los briófitos, indicadores de los distintos modelos climáticos experimentados por el bosque y de la evolución de éste tras la intervención humana, reflejada en la desaparición de ciertas especies o en la mayor proliferación de otras en ambientes nitrificados.

Otro papel fundamental que juegan los musgos como ayuda complementaria de la Arqueología, aunque sea de forma indirecta, es en la formación de turberas.

Las turberas son "bosques en miniatura», donde los musgos serían los árboles (Pelt, 1981). La turba se origina en los lugares húmedos y fríos, donde el agua estancada favorece el desarrollo de un género concreto de musgos, los esfagnos (Sphagnum sp.). Sus caulidios tienen un crecimiento más o menos continuo en sentido longitudinal pero, a medida que crecen, su base se va descomponiendo, creándose poco a poco la turba. Su espesor es variable, dentro de un rango de profundidad que oscila entre los cuarenta centímetros a más de diez metros, según sea la antigüedad de la turbera, en ocasiones de varios milenios.

Dichas turberas tienen la peculiaridad de albergar en realidad toda una flora especializada, testimonio de la época de las glaciaciones, que no sobreviviría en ningún otro medio. Tal es el caso de los Eriophorum, Andromeda y, sobre todo, de las conocidas "a:rapamoscas», especies pertenecientes al género Drosera, todas ellas carnívoras.

La turba, además, conserva perfectamente todas las estructuras fósiles, sean de la clase que sean, aunque principalmente los granos de polen. Es por ello que perfiles polínicos obtenidos en turberas han servido como fuente inexcusable de información para el estudio de los distintos 
periodos climáticos seguidos por nuestro planeta, sobre todo durante el Cuaternario, siendo una referencia muy válida para el estudio de la vegetación a lo largo del Pleistoceno y Holoceno. Además, resulta fácil datar, mediante la técnica del carbono 14, los diferentes pisos superpuestos de una turbera, por lo cual también es sencillo descubrir la edad de los fósiles de cada uno de los estratos.

Este procedimiento ha permitido reconstruir las grandes deforestaciones del Neolítico, para abrir campos de cultivo que llevaron aparejadas un notable descenso del polen arbóreo en las turberas, y un aumento simultáneo de polen de cereales (Pelt, 1981). Por el contrario, la regresión de tales actividades humanas supuso la recuperación del bosque si este hecho era posible, con lo que el número de pólenes arbóreos aumentaba de manera notable en la turbera.

La comparación de los perfiles obtenidos en las turberas con los diagramas polínicos efectuados a partir de perfiles procedentes de yacimientos arqueológicos cercanos a las turberas proporcionará un medio fácil de poder establecer correlaciones en la evolución de la vegetación a lo largo del Cuaternario, siendo mucho más fácil de datar en estos casos la aparición y efectos causados por actividades humanas sobre el medio ambiente.

Notables son también los métodos de investigación que usan las almohadillas de los briófitos, para estudiar la lluvia polínica, por su capacidad de captación y conservación del polen procedente de la vegetación circundante de tales biotopos almohadillados. Con tal información, referente como mucho a los últimos quince o veinte años, el interés de los diagramas polínicos aumenta, pues el estudio de la deposición polínica en niveles actuales gana en exactitud de manera realmente significativa. Dentro de este tipo de metodología se pueden destacar los trabajos de Carroll (1943), Burjachs (1988) y Straka y Kappen (1988).

\section{Hongos}

Todos los principales grupos fúngicos están representados en el registro fósil desde finales del Paleozoico, y muchos de ellos presentan una semejanza sorprendente con géneros existentes hoy día.

Los hongos fósiles más recientes suelen corresponder a formas epífitas. Dilcher (1965), estudiando hongos epífitos del Eoceno en adelante, ya intuía la posible relación de éstos con géneros modernos, pudiendo incluso en algunos casos, elaborar ciclos de vida completos de especies fósiles. Se han encontrado también restos fósiles de hongos parásitos, definidos por la presencia de haustorios (órganos de absorción). También han sido descubiertas, en estado de buena conservación, micorrizas fósiles (asociación simbiótica entre hifas fúngicas y raíces) (Harley, 1969).

Teniendo en cuenta que los hongos superiores son exigentes en cuanto a las condiciones ambientales en que han de desarrollarse, siendo de manera general organismos estenoicos, es decir, con una amplitud ecofisiológica muy estrecha; se comprenderá la gran importancia que puede tener la identificación en yacimientos arqueológicos de restos fósiles atribuibles a hongos.

Por lo general, requieren condiciones de humedad relativamente alta y rangos de temperatura definidos para cada especie, aunque no obstante, se han adaptado a todas las formas de vida posibles en la naturaleza, tanto acuáticas como terrestres. Su condición, en ciertas especies, de saprófitos, les hace dependientes de las comunidades de fanerógamas en las que habitan. Así, por ejemplo, la mayoría de las especies de los géneros Lactarius y Rusula, sólo se desarrollan sobre acículas de coníferas en descomposición. Así pues, la presencia de restos de estos hongos nos indicaría a su vez, con alta probabilidad, la existencia de comunidades de coníferas. Este hecho lo podríamos utilizar para definir no sólo el hábitat del hongo, sino el propio contexto humano si existiese relación posible con restos arqueológicos contemporáneos.

Otras especies son aún más exigentes. Así, por ejemplo, Pleurotus eringii se desarrolla sobre

\section{T. P., 1991, no 48}


raíces muertas del "cardo corredor" (Eryngium campestre), cuya presencia es indicativa de espacios abiertos algo nitrificados, derivados posiblemente de procesos antrópicos.

Ciertas especies de hongos están especializadas en vivir sobre madera. La relación entre el hongo y la planta leñosa que le va a servir de huésped comienza por la puesta en contacto de ambas. Las esporas del hongo apenas pesar, siendo llevadas por el aire a grandes distancias, encontrándose por todas partes. Sólo falta una puerta de entrada para penetrar la madera, y esta oportunidad se da al producirse heridas o lesiones en los árboles: cortes de poda, roturas por el peso, vientos, nevadas, mordeduras de animales o picaduras de insectos. Correlaciones entre la aparición masiva de restos fósiles atribuibles a esporas fúngicas, con los procesos que faciliten su entrada en la madera, podrían servir de base para la explicación de los fenómenos climáticos sufridos por el bosque, así como la posible intervención humana en procesos de tala. Hay hongos que crecen sólo sobre madera viva en desarrollo (Xanthochrous pini); otros perduran después de que el ataque haya ocasionado la muerte de los tejidos (Daedalea quercina), y otros solamente prosperan sobre madera muerta (Lenzites sepiaria). Observando los árboles afectados por procesos fúngicos se puede considerar cierta sucesión cronológica (García Rollán, 1984).

Mientras hay hongos que atacan indiferentemente a la mayoría de árboles (Armillariella mellea, Laetiporus sulphureus), otras especies sólo lo hacen a maderas determinadas: Fomitopsis pinicola y Phellinus pini sobre coniferas en pie, Mycena seynii y Collybia conigena sobre piñas semienterradas o algo podridas, Stereum hirsutum y Fistulina hepatica sobre robles en pie, etc.

Todos estos datos son de gran valor si se tiene en cuenta la presencia de hifas fúngicas, así como de esporas en maderas fósiles, aportando numerosas evidencias sobre el tipo de bosque en que podría irse desarrollando la actividad humana prehistórica. Así, Schweingruber y Pawlik (1977) observaron la presencia de hifas fúngicas y esporas en maderas no carbonizadas provenientes de sedimentos lacustres litorales del Neolítico en Suiza.

No obstante, surge un inconveniente que hay que tener muy en cuenta al realizar este tipo de estudios y es la posibilidad de que el desarrollo del hongo no sea sincrónico con el período al que pertenezca el resto arqueológico, sino que tenga lugar sobre maderas fosilizadas o no de períodos muy anteriores. Este tipo de datos puede suponer una distorsión en la información arqueoecológica. Por ello es preciso determinar ante qué tipo de restos atribuibles a criptógamas nos encontramos en cada caso.

Los hongos han sido recolectados y consumidos por el hombre desde tiempos inmemoriales (Müller y Loeffler, 1976). Las fermentaciones alcohólicas fueron conocidas por el hombre prehistórico que utilizó, en la mayoría de los casos, levaduras silvestres sin darse cuenta de su propia existencia, ya que éstas son microscópicas y su naturaleza biológica no ha sido advertida hasta fechas recientes. Sin embargo, los polinesios, que han usado las levaduras desde tiempos muy antiguos para descomponer el almidón de las semillas molidas, parecen haber sido excepcionales en cuanto a la utilización y prolif eración de dichos hongos (Baker, 1968).

Es evidente que los hongos han despertado una gran curiosidad en los hombres de todas las épocas, siendo objeto de numerosas leyendas, fantásticas creencias y espectaculares escándalos por los efectos farmacológicos e intoxicaciones producidos por ellos. Indudablemente, los primeros pobladores de la Tierra ya debieron conocer las setas, y como no, tratar de comprobar si eran o no comestibles, tal y como hacían con el resto de vegetales, aunque muchas veces les llevaría a la muerte.

Importantes descubrimientos relativos al uso alimenticio de la «lengua de buey» (Fistulina hepatica) se han llevado a cabo dentro del período perteneciente a la civilización lacustre en Suiza (Calonge, 1975).

La representación más antigua de un hongo llegada a nuestros días corresponde a una pintura mural de la tumba de un faraón de la XII dinastía, Amenemhet, que data del año 1450 a. C. (Calonge, 1975).

Ciertos pueblos, como los mayas, prestaron un culto ostensible a los hongos alucinógenos, desde el siglo $\mathrm{X}$ antes de la era cristiana. Numerosos son los datos descubiertos en Guatemala y Méjico, en 
forma de representaciones de setas en piedra, cerámica, frescos, etc., ya que el papel que los hongos jugaban en la mitología y religión de los mayas era notable. Tales hechos han quedado bien documentados (Lowy, 1971, 1974, 1977).

No podemos olvidar tampoco la influencia que los hongos jugaron en las civilizaciones griega y romana. En esta última se consumieron grandes cantidades de setas con fines alimenticios, como puede observarse aún en los frescos de Herculano, donde aparecen perfectamente representados varios ejemplares de nízcalo (Lactarius deliciosus), junto a faisanes. Datos como éste ayudan enormemente a definir el medio ambiente en que vivía el hombre, dada la ecología tan concreta que, en este caso, presentan los hongos. Las setas venenosas también dejaron su huella en la civilización romana, siendo célebre la muerte del emperador Claudio, envenenado tras el consumo de la toronja verde (Amanita phalloides).

También se han encontrado vestigios del uso de las setas en rituales mágicos en Borneo y Nueva Guinea, así como en el norte de Siberia, países en los cuales los hongos han desempeñado un importante papel en la aparición de las religiones primitivas.

\section{Líquenes}

Los líquenes, asociación simbiótica entre un alga (ficobionte) y un hongo (micobionte), son consorcios biológicos de amplia difusión, que se encuentran en una gran variedad de hábitats desde la región ártica a la antártica; tanto en rocas de desiertos, lava solidificada, cortezas de árboles y hasta en los mármoles de las minas de los templos antiguos de Delos (Alexopoulos y Mims, 1985).

Algunas especies que poseen algas verdeazuladas como ficobionte son muy importantes en ciertos ecosistemas, pues aportan la mayor parte del nitrógeno fijado (costras de líquenes terrícolas de los desiertos, el género Lobaria en los bosques de abeto de Douglas del noreste americano, etc.).

Se ha demostrado, por otra parte, que desempeñan un papel fundamental como indicadores de la polución del aire, habiéndose por ello incrementado en los últimos años el número de estudios sobre la distribución de líquenes en ciudades y el efecto de los distintos contaminantes sobre los talos liquénicos. Tanto hongos, musgos, como líquenes epífitos han demostrado las reacciones más sensibles a los contaminantes ambientales, estando por ello generalmente ausentes en el centro de las ciudades. En cambio, los musgos y líquenes saxícolas se adaptan mejor al medio urbano, pues éste les facilita un mayor número de lugares en los que poder desarrollarse, tales como vallas, edificios, etc. Son por ello menos sensibles a la contaminación que los epífitos. Los hongos parásitos y saprófitos se extienden igualmente bien por tales centros urbanos (Sukopp y Werner, 1989).

\section{Pteridófitos}

Los pteridófitos (licopodios, equisetos o colas de caballo, folicales o helechos...) son también de enorme importancia como elementos constituyentes de comunidades vegetales que, en ciertas ocasiones, quedan definidas por la presencia de una o varias especies de este grupo botánico.

Es evidente que la mayoría de pteridófitos poseen una distribución más amplia que la de las fanerógamas. Sin embargo, éstas, por su relativa modernidad, poseen áreas que podrían catalogarse de inestables, mientras los pteridófitos, más antiguos, las presentan más permanentes (Pichi Sermolli y Salvo, 1987-88).

Precisamente por su arcaismo, la distribución de las especies de helechos es la resultante de la combinación de la influencia de diferentes eventos geológicos y de la capacidad adaptativa de cada especie. Es aquí, donde radica el alto valor de los pteridófitos como indicadores ecológicos. Conociendo el área actual de las especies constituyentes de la pteridoflora de un territorio determinado, podemos aproximarnos a los acontecimientos históricos allí acaecidos. Bajo este punto de vista, hay 
que destacar aquellas especies que, por su carácter relíctico o endémico, suponen una fuente de información notable. Así, ciertos elementos de la pteridoflora han sido relegados a áreas puntuales, refugios donde se siguen manteniendo condiciones similares a las previas. Dichas especies, consideradas relícticas, nos hablan de estados climáticos anteriores y la forma y modo, en que éstos fueron evolucionando.

Pichi Sermolli y Salvo (1987-88) realizan un detallado análisis histórico de la pteridoflora ibérica, subdividiendo las especies presentes en el Mediterráneo durante el Cuaternario, en tres grupos (heterocóricas, circumboreales y mediterráneas y de regiones próximas). La importancia de dicho trabajo radica en los numerosos datos aportados sobre la ecología de los pteridófitos, su origen y colonización, de la Región Mediterránea, y sobre todo, en la cita de aquellas especies cuya dispersión se ha visto influenciada por una acción antropógena.

Algunas especies de helechos están adaptadas a la vida cavernícola, donde la luz parece ser el principal factor limitante de la vida fotoautótrofa. Pero en los climas mediterráneos, la sequía estival y las altas temperatuas hacen que la humedad relativa baje, con lo que los vegetales menos resistentes deben buscar refugio en el interior de cuevas, donde la humedad está asegurada y se prevén pocas fluctuaciones. Ello da lugar a comunidades cavernícolas con las que muy posiblemente conviviría el hombre primitivo refugiado en tales cuevas. Así, por ejemplo, dos especies de las vulgarmente llamadas "lenguas de ciervo», Phyllitis scolopendrium y Phyllitis sagitata, están adaptadas a este tipo de vida cavernícola. En la franja más superficial de la cueva suelen acompañarse de un cortejo de helechos tales como Adiantum capillus-veneris, Asplenium trichomanes, Ceterach officinarum, etc.

Otras especies de helechos muy comunes en los diagramas polínicos son el género Polypodium y el helecho común (Pteridium aquilinum). El primero denota con su presencia, en ciertos casos realmente exuberante. Pues supera con creces al resto de especies fanerógamas herbáceas en cuanto a sus porcentajes, altas condiciones de humedad edáfica y ambiental. En este sentido, aumentos significativos en los niveles porcentuales de Polypodium pueden ser interpretados como un mayor progreso del bosque ripario durante el Subboreal, como altas condiciones de humedad en el interior del Quercetum mixtum durante el Atlántico, etc.; siempre teniendo en cuenta que tales datos han de sumarse a aquellos aportados por las formaciones arbóreas y arbustivas, que encontrarían un valioso aliado en la información facilitada por Polypodium.

Por su parte, Pteridium aquilinum, es una especie pionera tras situaciones de quema del bosque, sobre todo si estos incendios son consecuencia de actividades humanas, pues igualmente posee cierto carácter nitrófilo. Junto con Asphodelus, la aparición del helecho común sería indicativa del comienzo y posterior desarrollo de procesos antrópicos de tipo deforestador, utilizando el fuego como medio de clareo del bosque, obteniendo así terreno cultivable para la agricultura. Sería, por tanto, un dato muy valioso para establecer cronológicamente el comienzo de las actividades agrosilvopastoriles.

\section{CONCLUSIONES}

Si bien es cierto el papel enriquecedor con que contribuye la Arqueología a desvelar incógnitas acerca de la dinámica evolutiva de los grupos humanos, también es relevante el soporte multidisciplinario que ha incorporado la Arqueoecología al conocimiento del pasado histórico del hombre y su proceso de evolución sobre el medio terrestre, como piezas clave de la dinámica de los sistemas biológicos donde ha estado integrado.

La Criptogamia como ciencia encargada de la investigación de elementos biológicos pertenecientes a diversos hábitats utilizados por el hombre, en su proceso de desarrollo, puede suponer un recurso de apoyo muy útil para completar las interpretaciones arqueoecológicas, a la hora de precisar en la

T. P., 1991, $\mathrm{n}^{2} 48$ 
reconstrucción de paleoambientes, dado que las plantas criptógamas funcionarían como indicadores microclimáticos, susceptibles de aprovechamiento humano.

La Palinología sería la herramienta que facilitaría el análisis de la contribución que hace la Criptogamia a los objetivos de la Arqueoecología.

No podemos, pues, dejar de nombrar algunas especies o grupos botánicos que poseen cualidades más prometedoras para ser utilizadas con tal fin.

Un grupo interesante es el de los dinoflagelados, cuyas formas fósiles se presentan mayoritariamente en forma de quistes, de superficie lisa, granular o reticulada. La formación de los quistes suele responder a condiciones adversas del medio. En un principio estas formaciones se agruparon bajo el nombre de "histricosferos", y su posición sistemática no estaba muy clara, aunque se les consideraba afines a los dinoflagelados. Las diatomeas marinas deben igualmente destacarse, pues alcanzaron un gran desarrollo tanto en el Terciario como en períodos interglaciares, formando depósitos que se conocen bajo el apelativo de tierra de diatomeas, trípoli, diatomita, harina fósil, etc., muy explotados por el hombre.

Entre los pteridófitos, los géneros más frecuentes y cuya presencia queda reflejada en los diagramas polínicos son: Botrychium, Equisetum, Isoetes, Lycopodium, Osmunda, Polypodium, Selaginella y Pteridium. Ybert (1988) se basó en el género Isoetes para conocer el modelado lacustre y los cambios climáticos acaecidos en el lago Titicaca.

No obstante, las dificultades para utilizar las criptógamas como fuente de información arqueoecológica siguen aún vigentes. El desinterés que su estudio ha tenido dentro de la propia Palinología, donde la Criptogamia ha sido relegada a un segundo término y, por tanto, obviada su posible ayuda como información complementaria de la facilitada por las fanerógamas.

Falta material comparativo con el que establecer determinaciones hasta niveles genéricos e incluso específicos de las esporas observadas. Es por ello, que se debe promover la creación y uso de colecciones comparativas, así como la publicación de éstas, a fin de un mayor conocimiento general, incluso para el propio arqueólogo.

Igualmente se debe abogar por una mayor presencia de las criptógamas en los diagramas polínicos, pues ésta queda reducida en la mayoría de los casos a una mera alusión. Con el apelativo de "esporas", "monoletes» o "triletes" se suelen agrupar géneros cuya separación taxonómica sería realmente importante, dada las cualidades de indicación ecológica de las criptógamas.

Se debe investigar sobre un nuevo método de tratamiento químico, pues los actuales no son del todo válidos para ciertas criptógamas. Muchas algas, entre ellas las diatomeas, llegan a destruirse con el método actual. En este sentido, cabe lugar una mayor profundización en todo lo relativo a la metodología.

La nueva visión que ofrece la presencia humana, de la vida y de los frágiles equilibrios de los sistemas ecológicos implica una interdependencia entre los grupos humanos y los recursos naturales del hábitat que ocupan. De aquí el interés por seguir indagando nuevos centros de información acerca de esta interdependencia.

\section{BIBLIOGRAFIA}

BAKER, H. G. (1968): Las plantas y la civilización. Herrero Hnos. Sucesores, S. A. México.

Berglund, B. E. (1977): "Biological/paleoecological analyses for moder archaeological research". In I. V. OLSSON \& V. Mejdahl (eds.): Proceedings of the Nordic Conference on Thermoluminescent Dating an other Archaeometric Methods. Uppsala: 38-44.

Bold, H. C. y Wynne, M. J. (1985): Introduction to the Algae. Prentice-Hall, Inc. Englewood Cliff. New Jersey.

BurJachs, F. (1988): "Análisis polínico de los niveles cerámicos de la "Cova 120" (Alta Garrotxa, Catalunya)». Actas del VI Simposio de Palinología, A.P.L.E. Salamanca.

Butzer, K. (1964): Environment and Archaeology: An Introduction to Pleistocene Geography. Chicago.

CAlonge, F. D. (1975): Hongos de nuestros campos y bosques. ICONA, Madrid. 
CARroll G. (1943): "The use of Bryophytic polsters and mats in the study of recent pollen deposition". American Journal of Botany, 30: 361-366.

Cavalier-Smith, T. (1974): «Eucariote Kingdoms: seven or nine?». BioSystems, 14: 461-481.

- (1983): "A 6-kingdoms classification and a unified phylogeny». In H. E. A. SCHEENK \& W. SCHWEMMLER (eds.): Endocytobiology II: Intracellular Space as oligogenetic ecosystem, 2: 1024-1037, Walter de Gruyter. Berlin \& New York.

Corliss, J. O. (1984): «The Kingdom Protista and its 45 Phyla». BioSystems, 17: 87-126.

Cronouist, A. (1978): Botánica básica. Compañia Editorial Continental, S. A. México.

D’Antoni, H. L. (1979): Arqueoecología. I.N.A.M. México.

Des AbBayes, H. \& col. (1989): Botánica: Vegetales inferiores. Editorial Reverté, S. A. Barcelona.

Dilcher, D. L. (1965): «Epiphyllous fungi from Eocene deposits in Western Tennessee, U.S.A.». Paleontographica, 116 B: $1-54$.

Dupre Ollivier, M. (1988): «Apports de la palynologie à la connaissance du paléoenvironnment végétal holocène de la région de Valence (Espagne)". Inst. fr. Pondichéry, trav. sec. sci. tech., 25: 55-63.

EDWARDS, P. E. (1976): "A classification of plants into higher taxa based on cytological and biochemical criteria». Taxon, 25: 542-592.

FERNÁNDEZ-GALIANO, D. (1990): «Las nuevas clasificaciones de los organismos eucarióticos unicelulares. Protistología versus Protozoología". Bol R. Soc. Esp. Hist. Nat. (Sec. Biol.), 85 (1-4): 107-125.

García Rollán, M. (1984): Setas de los árboles. M.A.P.A., Publicaciones de Extensión Agraria. Madrid.

GRAY, J. (1962): «Fossil polen and archaeology». Archaeology, 15 (1): 16-26.

HAECKEL, E. (1866): Generelle Morphologie der Organismen (2 vols.), G. Reimer. Berlín.

- (1878): Das Protistenreich, Gunther. Leipzig.

HARLEY, J. L. (1969): The Biology of Mycorrhiza. Leonard Hill. London.

LEEDALE, G. F. (1974): «How many are the Kingdoms of organism?». Taxon, 23: 261-270.

López García, P. (1980): "Estudio de semillas prehistóricas en algunos yacimientos españoles». Trabajos de Prehistoria, 37: 419-432.

- (1986): "Estudio palinológico del Holoceno español a través del análisis de yacimientos arqueológicos». Trabajos de Prehistoria, 43: 143-158.

Lowy, B. (1971): «New records of mushroom stones from Guatemala». Mycologia, 63: 983-993.

- (1974): "Amanita muscaria and the thunderbolt legend in Guatemala and Mexico». Mycologia, 66: $188-190$.

- (1977): «Hallucinogenic mushrooms in Guatemala». J. Psychedelic Drugs, 9: 123-125.

MaRGalef, R. (1956): «Oscilaciones del clima postglacial del noroeste de España registradas en los sedimentos de la Ría de Vigon. Zephyrus, 7: 5-9.

Margulis, L. (1974): «Five-Kingdoms classification and the origin and evolution of cells». Evol. Biol., 7: 45-78.

- (1981): Symbiosis in cell evolution. Freeman. San Francisco.

Müller, E. y Loeffler, W. (1976): Micología. Editorial Omega, S. A. Barcelona.

PELT, J. M. (1981): Las plantas: "Amores y civilizaciones vegetales». Biblioteca Científica Salvat. Barcelona.

Pichi-Sermolli, L. y Salvo, A. E. (1987-88): "El valor biogeográfico de la pteridoflora ibérica». Lazaroa, 10: 187205.

Puytorac, P. \& col. (1987): Précis de Protistologie. Fondation Singer-Polignac. París.

RiverA D. \& col. (1988): “Arqueobotánica y Paleoetnobotánica en el s ureste de España, datos preliminares». Trabajos de Prehistoria, 45: 317-334.

RoN, E. \& col. (1987): «Urban Bryophytes in Spanish towns». Symposia Eiologica Hungarica, 35: $727-753$.

SCHOFIELD, W. B. (1985): Introduction to Bryology. Macmillan Publishing Company. New York.

SCHWEIngruber, F. H. y PAWLIK, B. (1977): "La reconstitution de la végétation dans les environs inmédiats d'une station néolithique au Lac de Zurich basée sur les bois et graines fossiles». In Approche Ecologique de L'Homme Fossile. Suplement au Bulletin A.F.E.Q., 47: 293-296, Paris.

Sмiтh, G. M. (1955): Botanica criptogamica (2 vols.), Fundaçao Calouste Gulbenkian. Lisboa.

STRAEVER, S. (1971): «Comments on archaeological data requirements and research strategy». American Antiquity, 36: 9-16. Washington.

STRAKA, H. y KAPPEN, L. (1988): «Analyse palynologique de coussins de mousse dans l'Antarctide». Inst. fr. Pondichéry, trav. sec. sci. tech., 25: 295-300.

Sukopp, H. y WeRnER, P. (1989): Naturaleza en las ciudades. Monografías de la Dirección General de Medio Ambiente, M.O.P.U. Madrid.

WhitTAKER, R. H. (1969): «New concepts of Kingdoms of organism». Science, 163: 150-159.

WhitTaker, R. H. y MARgulis, L. (1978): «Protist classification and the Kingdoms of organisms». BioSystems, 10: 3 18.

YBERT, J. P. (1988): «Apports de la palynologie à la connaisance de'l histoire du lac Titicaca (Bolivie-Pérou) au cours du Quaternaire récent". Inst. fr. Pondichéry, trav. sec. sci. tech., 25: 139-150. 